\title{
Production of transparent exopolymer particles (TEP) in cultures of Chaetoceros calcitrans under nitrogen limitation
}

\author{
Alfonso Corzo*, Jose Antonio Morillo, Susana Rodríguez \\ Department of Ecology, Faculty of Marine Science, University of Cádiz, 11510 Puerto Real, Spain
}

\begin{abstract}
Transparent exopolymer particles (TEP) are considered to be generated abiotically from dissolved extracellular polysaccharides released mainly by phytoplankton. TEP may affect the aggregation rate of particles and therefore influence the flux of organic carbon to the deep ocean. The role of $\mathrm{NO}_{3}{ }^{-}$limitation in the production of TEP by the marine diatom Chaetoceros calcitrans was investigated. C. calcitrans was grown in batch cultures with different initial nitrate concentrations $(25,75$, 150, 250 and $450 \mu \mathrm{mol} \mathrm{l}^{-1}$ ). Nitrate affected the production of TEP in 2 distinct ways. The initial specific growth rate and maximum concentration of biomass (as estimated by chlorophyll $a$, cell number, total particulate carbon or total particulate nitrogen) reached in every culture was directly dependent on the initial $\mathrm{NO}_{3}{ }^{-}$concentration. Maximum TEP concentration followed this trend, and was significantly linearly correlated with several biomass-related variables and with the initial $\mathrm{NO}_{3}{ }^{-}$concentration. However, despite the general trend of direct covariation between TEP concentration and phytoplankton biomass, $\mathrm{NO}_{3}{ }^{-}$has a more specific effect. A close examination of the exponential phase shows that the net production of TEP per biomass was higher in N-limited cultures. In the N-sufficient cultures, during Day 2, there was even a decrease in the concentration of TEP per unit of biomass with respect to the inoculum. Our results support the hypothesis that, under N-limitation, a large proportion of the photosynthetically fixed carbon is channeled to TEP. The concentration of carbohydrate in the particulate fraction $(\mathrm{PCH})$ was larger in $\mathrm{N}$-limited cultures. The effect was clearer during exponential growth. In this phase there was a good agreement between the response of TEP and PCH to $\mathrm{N}$ limitation. Unlike TEP, PCH decreased sharply during the stationary and senescent phases. The decrease of $\mathrm{PCH}$ was associated with an increase in dissolved organic carbon and an increase in the number of bacteria in the cultures.
\end{abstract}

KEY WORDS: TEP · Transparent expolymer particles $\cdot$ Nitrogen limitation $\cdot$ Chaetoceros calcitrans

Resale or republication not permitted without written consent of the publisher

\section{INTRODUCTION}

Transparent exopolymer particles (TEP) are now known to be abundant in the ocean (Alldredge et al. 1993). These particles had previously gone unnoticed due to their relative invisibility. However, after staining with alcian blue, a dye specific for polysaccharides, TEP could be quantified and the question of their ecological importance addressed. The presence of TEP is known to influence the aggregation rate of particles

*E-mail: alfonso.corzo@uca.es
(Kiørboe \& Hansen 1993, Dam \& Drapeau 1995, Logan et al. 1995, Passow \& Alldredge 1995b) and particle size spectrum (Passow \& Alldredge 1994). Thus, TEP may affect the flux of organic carbon from the euphotic layer to the deep ocean, and help to explain the discrepancy between observed vertical flux and those predicted by aggregation-sedimentation models (Jackson 1990, Hill 1992, Logan et al. 1995). In addition TEP may be consumed by protozoans and copepods (Decho \& Moriarty 1990, Shimeta 1993, Tranvik et al. 1993) and, thus, it may represent an alternative pathway for the transfer of carbon and energy from dis- 
solved organic carbon (DOC) to a higher trophic level (Mari 1999).

High TEP concentration is frequently associated with the final phase of diatom blooms in the ocean (Passow et al. 1994, Mari \& Burd 1998), and with the stationary and senescent stage in cultures (Waite et al. 1995, Hong et al. 1997) and mesocosm experiments (Passow \& Alldredge 1995b). TEP are formed abiotically from dissolved extracellular polysaccharides released by phytoplankton and bacteria (Passow et al. 1994, Passow 2000). Bubble scavenging (Mopper et al. 1995, Zhou et al. 1998, Mari 1999) has been suggested as a mechanism responsible for TEP formation from dissolved extracellular polysaccharides. However, in a bloom dominated by Phaeocystis antarctica, the sloughing and disintegration of the colonial matrix was considered an important source of TEP as well (Hong et al. 1997). Dissolved organic matter may undergo spontaneous gelation to form TEP (Chin et al. 1998). Finally, Passow (2000) reported the formation of TEP by laminar shear from precursors smaller than $0.2 \mu \mathrm{m}$.

Phytoplankton exudes a wide range of organic compounds that can vary with its physiological state (Nalewajko \& Lean 1972, Hoagland et al. 1993). Polysaccharides can represent up to $87 \%$ of total carbohydrates released in the stationary phase (Vieira \& Myklestad 1986). However, there are large differences in the amount of carbohydrates produced by different species. The partition of carbohydrate production between an internal pool and the fraction released extracellularly depends upon culture conditions (Myklestad 1974). The protein:carbohydrate ratio has been shown to decrease as the growth rate decreases, both in batch and in continuous cultures under nitrogen limitation (Caperon \& Meyer 1972, Myklestad \& Haug 1972, Myklestad 1974). Mari \& Burd (1998) showed in situ evidence for TEP abundance being higher when nitrate and the inorganic N:P ratio were low in the surface mixed layer. Since TEP are mainly composed of polysaccharides, it has been speculated that the production of TEP would be enhanced when cell growth is N-limited. The objective of this study was to test this hypothesis on batch cultures of the diatom Chaetoceros calcitrans.

Chaetoceros calcitrans was selected because it produced the largest amount of mucus-like material of the several diatom species we surveyed (authors' unpubl. results). Additionally, Chaetoceros is a relatively wellstudied genus from the point of view of carbohydrate production, stickiness, and mean sinking rate. In response to $\mathrm{N}$ limitation, several species of Chaetoceros have been shown to (1) increase the amount of total cell carbohydrates (Myklestad \& Haug 1972, Myklestad 1974, Vieira \& Myklestad 1986), (2) in- crease the amount of released free extracellular polysaccharides (Myklestad \& Haug 1972, Myklestad 1974), and (3) specifically increase the sugar-containing compounds on the cell surface (Waite et al. 1995). Furthermore, nutrient limitation affects the stickiness of several species of phytoplankton (Kiørboe et al. 1990), and the mean sinking rate of several species of diatoms including C. gracilis (Bienfang et al. 1982). Aggregate formation in cultures of $C$. affinis and $C$. gracilis depends on the presence of TEP (Kiørboe \& Hansen 1993, Crocker \& Passow 1995). However, Kiørboe et al. (1998) did not find a clear correlation between TEP concentration and stickiness in a natural bloom dominated by Chaetoceros spp.

\section{MATERIAL AND METHODS}

Growth conditions and experimental design. Unialgal batch cultures $(2000 \mathrm{ml})$ of Chaetoceros calcitrans were grown in F/4 medium (Guillard \& Ryther 1962), and prepared with filtered $(0.2 \mu \mathrm{m})$ seawater, except for nitrogen that was supplied as $\mathrm{NaNO}_{3}$ at concentrations of $25,75,150,250$ and $450 \mu \mathrm{mol} \mathrm{l}^{-1}$, producing $\mathrm{N}: \mathrm{P}$ stoichiometric ratios of $1.6,5,10,16.6$ and 30 (atomic ratios) respectively. Silica was provided at an initial concentration of $350 \mu \mathrm{M}$ to avoid silica limitation. Cultures were maintained at $17^{\circ} \mathrm{C}$ in continuous light (Sylvania Gro-Lux F30W/GRO) at a photon flux density of $150 \mu \mathrm{mol} \mathrm{m} \mathrm{m}^{-1}$ (spherical sensor LI-COR SPQA 1100 connected to a DataLogger LI-COR 1000). Cultures were ventilated with air filtered through $0.2 \mu \mathrm{m}$ filters (Millipore) to avoid $\mathrm{CO}_{2}$ limitation and to guarantee a good mix during growth. The intensity of bubbling was carefully adjusted to produce the same apparent turbulence in all cultures. Samples were taken from the cultures at different stages and processed according to the following methods.

Cell abundance. Chaetoceros calcitrans abundance was determined both by microscopic observation with a Neubauer hemocytometer, and by flow cytometry using $2 \%$ glutaraldehyde fixed samples stored in liquid nitrogen (Vaulot et al. 1989, Corzo et al. 1999), with very good agreement between both techniques $(\mathrm{r}=$ 0.95). Bacteria enumeration was done by flow cytometry, staining bacterial DNA with SYTO-13 (Molecular Probes) according to del Giorgio et al. (1996).

The quantification of bacteria reported in this study corresponds mainly to free-living bacteria, although some aggregates might disintegrate while passing through the flow chamber and tubing of the flow cytometer. Attached bacteria were reported to be less than $10 \%$ of the total bacterial community both in mesocosm studies (Smith et al. 1995) and in the ocean (Hodson et al. 1981). This should result in a small 
underestimation of the total number if diatom cultures can be compared in this aspect to both mesocosm experiments and the ocean.

Pigments. Chlorophyll was determined spectrophotometrically. A volume of culture $(20$ to $40 \mathrm{ml}$, depending on the expected density of cells) was filtered on a Whatman GF/F glass-fiber filter. The filter was placed in $90 \%$ acetone and left overnight in the dark at $4^{\circ} \mathrm{C}$. The concentration of chlorophyll a ( $\mathrm{chl} a)$ in the extracts was calculated using the dichromatic equation provided by Jeffrey \& Humphrey (1975). Samples were analyzed in duplicate.

Carbon and nitrogen in the particulate fraction. The particulate fraction was collected in duplicate by filtration on Whatman GF/F (25 mm) pre-combusted filters $\left(4 \mathrm{~h}\right.$ at $\left.450^{\circ} \mathrm{C}\right)$. The filters were then stored frozen at $-20^{\circ} \mathrm{C}$ for later analysis. Total particulate carbon (TPC) and nitrogen (TPN) were determined by means of a CNH Perkin-Elmer 240-C elemental analyzer.

Carbohydrates in the particulate fraction. The concentration of carbohydrate in the particulate fraction was determined by a phenol-sulfuric assay (Dubois et al. 1956). Two replicates were filtered on Whatman $\mathrm{GF} / \mathrm{F}$ filters and stored at $-20^{\circ} \mathrm{C}$ until analysis. Glucose was used for the calibration curve.

Concentration of TEP. TEP concentration was measured according to the dye-binding assay (Passow \& Alldredge 1995a). Samples (about $30 \mathrm{ml}$ ) obtained from the cultures at different times were fixed with $4 \%$ formaldehyde for later processing. All samples were processed within 1 mo using the same calibration curve. The particulate fraction was retained on $0.4 \mu \mathrm{m}$ polycarbonate filters (Poretic) by filtration under low pressure $(<100 \mathrm{~mm} \mathrm{Hg})$. Volumes ranging from 0.5 to $3 \mathrm{ml}$ were generally enough to obtain a good level of absorbance, except when cell density was very low at the onset of the cultures. In that case, $10 \mathrm{ml}$ was filtered as described above. Immediately after filtration, $500 \mu \mathrm{l}$ of an alcian blue freshly made solution $(0.03 \mathrm{~g}$ alcian blue dissolved in $150 \mathrm{ml}$ of $0.06 \%$ acetic acid, prefiltered through $0.22 \mu \mathrm{m}$ poresize filters) was added to the particulate fraction retained onto the polycarbonate filter and allowed to react for $2 \mathrm{~s}$. The excess of dye was immediately washed out by successive filtration of 2 aliquots of $1 \mathrm{ml}$ distilled water filtered through $0.22 \mu \mathrm{m}$ pore-size filters. At that stage the filter can be kept frozen $\left(-20^{\circ} \mathrm{C}\right)$ for several weeks until further processing. The alcian blue was released from its binding sites on the particulate fraction by immersing each filter in $3 \mathrm{ml}$ of $80 \%$ sulfuric acid for $2 \mathrm{~h}$ at continuous agitation at room temperature. Finally the amount of alcian blue released was determined by measuring the absorbance at $787 \mathrm{~nm}$. To account for the binding capacity of the polycarbonate filter several blanks were processed as described above. All samples were analyzed in triplicate. TEP values are expressed as xanthan gum weight equivalent calculated by means of a calibration curve according to Passow \& Alldredge (1995a).

Inorganic nutrients. Water samples for inorganic nutrients were collected after filtration through Whatman GF/F filters. The aliquots for inorganic nutrients were stored frozen $\left(-20^{\circ} \mathrm{C}\right)$ until analysis by means of a TRAACS 800 Bran Luebbe autoanalyser following standard protocols (Grasshoff et al. 1983).

Dissolved organic carbon. Water samples for DOC were collected after filtration on Whatman GF/F filters. Samples were acidified with $\mathrm{H}_{3} \mathrm{PO}_{4}$ and stored frozen at $-20^{\circ} \mathrm{C}$ until analysis using the high temperature catalytic oxidation method (Chen \& Wagersky 1996) with a TOC-5050 Shimadzu Analyser. All the material in contact with the sample for DOC required a special cleaning procedure and treatment. The Whatman filters were pre-combusted at $450^{\circ} \mathrm{C}$ for $4 \mathrm{~h}_{\text {; glass test }}$ tubes, caps and o-rings were washed with $10 \% \mathrm{HCl}$ for $24 \mathrm{~h}$ and soaked with abundant Milli-Q water. Caps and o-rings were dried at $60^{\circ} \mathrm{C}$ and the glass test tubes were dried at $550^{\circ} \mathrm{C}$. The test tubes were kept closed until the collection of the samples. The filtration apparatus was treated similarly to the glass tubes.

\section{RESULTS}

\section{Growth}

Abundance of Chaetoceros calcitrans was dependent on the initial nitrate concentration, and increased exponentially up to Day 7 after inoculation (Fig. 1A). During this phase both nitrate (Fig. 1C) and phosphate (results not shown) were depleted from the external medium. After this day, cultures entered the stationary and senescent phase. This pattern was observed both in the number of cells and in the concentration of other biomass-related variables like chl a (Fig. 1B). The initial $\mathrm{NO}_{3}{ }^{-}$concentration or, alternatively, the initial stoichiometric ratio at which both $\mathrm{NO}_{3}{ }^{-}$and $\mathrm{PO}_{4}{ }^{3-}$ were provided seems to affect the relative duration of the stationary and senescent growth phases. The larger the $\mathrm{N}: \mathrm{P}$ ratio of resources, the shorter the stationary phase.

The specific growth rate $(\mu)$ calculated for the exponential phase ranged from 0.47 to $0.7 \mathrm{~d}^{-1}$. $\mu$ was related to the initial $\mathrm{NO}_{3}{ }^{-}$concentration according to the Monod equation, $\mu=\left(\mu_{\max } S\right) /\left(K_{\mathrm{s}}+S\right)$ where $\mu_{\max }=$ maximum specific growth rate, $K_{\mathrm{s}}=$ half-saturation constant, and $S=$ substrate concentration (result not shown). The experimental data were fitted to Monod kinetics by a nonlinear regression Levenberg-Marquardt algorithm $\left(\mathrm{r}^{2}=\right.$ $\left.0.99, K_{\mathrm{s}}=11.7 \pm 2.8 \mu \mathrm{M} \mathrm{NO}_{3}^{-}, \mu_{\max }=0.67 \mathrm{~d}^{-1}\right)$. 


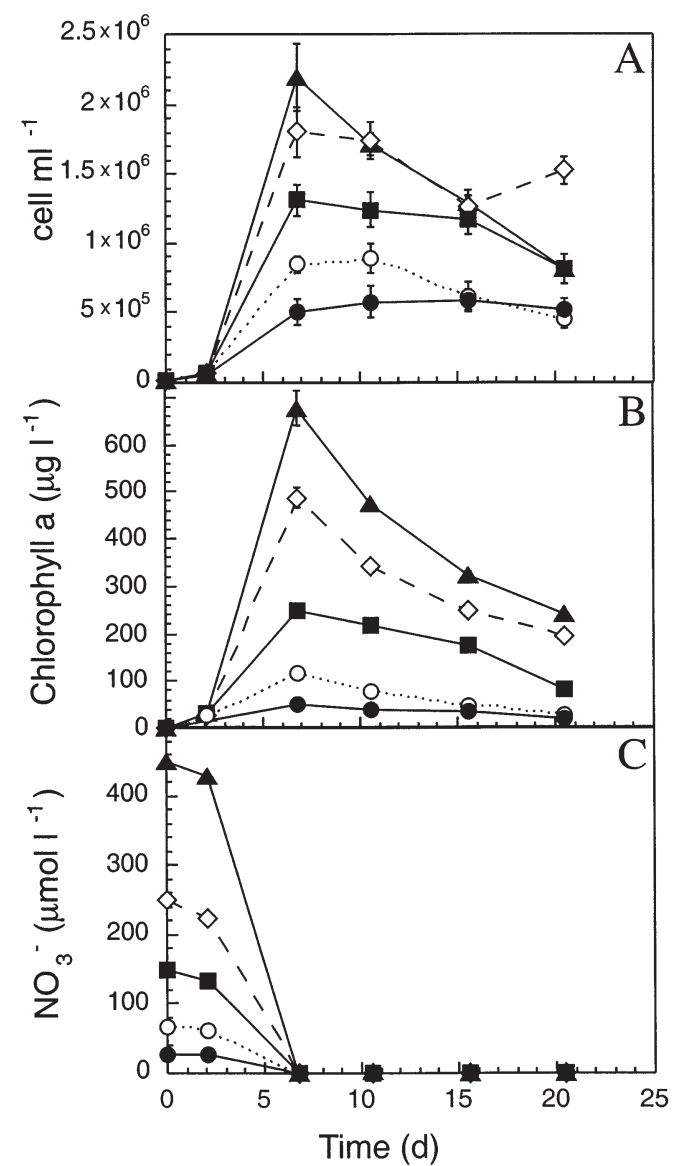

Fig. 1. Time course of (A) cell number, (B) chlorophyll $a$ and (C) $\mathrm{NO}_{3}{ }^{-}$concentration in batch cultures of Chaetoceros calcitrans provided with $25(\bullet), 75(\mathbf{O}), 150(\mathbf{\square}), 250(\diamond)$ and $450(\boldsymbol{\Delta}) \mu \mathrm{M} \mathrm{NO}_{3}{ }^{-}$at time zero. Plotted data are the mean of 2 replicates. Standard deviation is represented as a bar when it exceeds the symbol size

\section{$\mathrm{C}: \mathrm{N}$ stoichiometric composition of the particulate fraction}

The TPC and TPN contents in the particulate fraction were related to the initial $\mathrm{NO}_{3}{ }^{-}$concentration supplied to the cultures (Fig. 2). In general, the changes in TPC and TPN during the evolution of the cultures were similar to other biomass-related variables like number of cells and chlorophyll (Fig. 1). The major differences were found during the senescent phase. TPC reached maximum concentration on Day 7 for cultures at 25, 75 and $150 \mu \mathrm{M}$, and later, on Day 10, for cultures at 250 and $450 \mu \mathrm{M}$. After this date, throughout stationary and senescent phases, the TPC concentration remained fairly constant compared to the large decrease observed in cell numbers and chlorophyll, mainly in cultures at 250 and $450 \mu \mathrm{M}$. This observation suggests that part of the cellular carbon produced during the exponential phase remained in the particulate fraction during the senescent

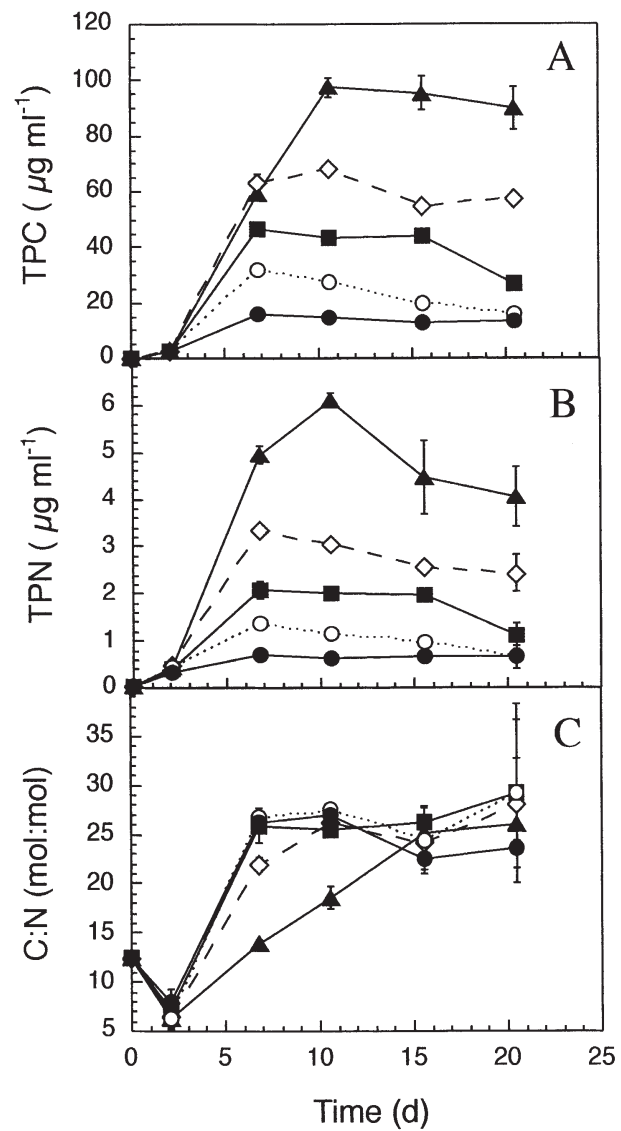

Fig. 2. Time course of (A) total particulate carbon (TPC) and (B) nitrogen (TPN) referred to volume of culture and (C) C:N ratio in batch cultures of Chaetoceros calcitrans grown at 25 (@), $75(0), 150(\mathbf{\square}), 250(\diamond)$ and $450(\mathbf{\Delta}) \mu \mathrm{M}$ intital $\mathrm{NO}_{3}{ }^{-}$concentration. Plotted data are the mean of 2 replicates. Standard deviation is represented as a bar when it exceeds the symbol size

phase but in a non-living compartment. TPN followed basically the same trend as TPC, except that a larger relative decrease was observed in the senescent phase.

The stoichiometric C:N ratio of the particulate fraction, initially close to 12 , showed a decrease during the second day, down to values close to the Redfield ratio, in response to the initial $\mathrm{NO}_{3}{ }^{-}$pulse (Fig. 2C). However, at the end of the observed exponential phase its value was higher than 20 for all cultures, except for Culture 5, which received the higher $\mathrm{NO}_{3}{ }^{-}$initial concentration and was P-limited as well. Later, the C:N ratio remained basically unchanged in all cultures up to the end of the experiment.

\section{TEP concentration}

Two characteristics are remarkable in the change of TEP concentration versus time: (1) The kinetics of TEP 


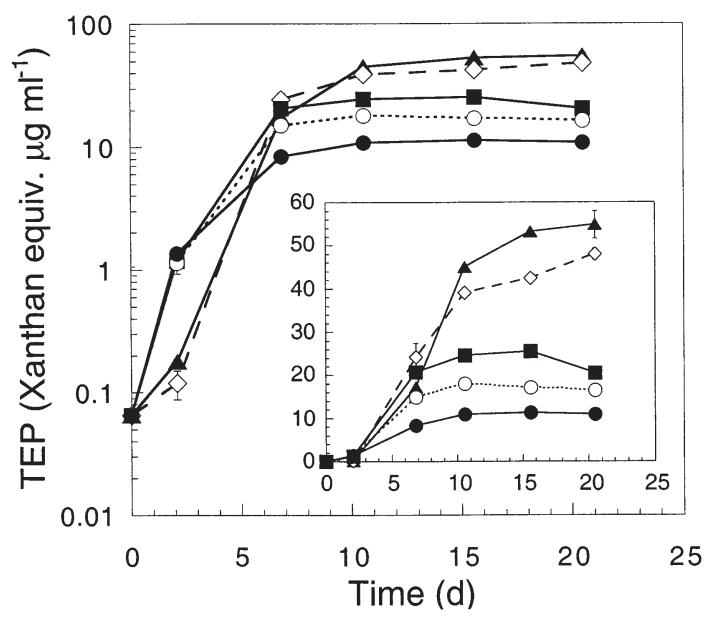

Fig. 3. Concentration of transparent exopolymeric particles (TEP) per volume (data in a log scale) with time in batch cultures of Chaetoceros calcitrans grown at $25(\bullet), 75(\bigcirc), 150$ (ם), $250(\diamond)$ and $450(\boldsymbol{\Delta}) \mu \mathrm{M}$ initial $\mathrm{NO}_{3}{ }^{-}$concentration. Data in lineal scale are presented in the inserted graph. Plotted data are the mean of 4 replicates. Standard deviation is represented as a bar when it exceeds the symbol size

and that of biomass-related variables differed in senescent phase. While there was a large decrease in cell number and chlorophyll during the senescent phase, mainly in the nitrogen sufficient cultures, the concentration of TEP remained almost constant or slightly increased. (2) The magnitude of initial $\mathrm{NO}_{3}{ }^{-}$pulse that cells received when transferred to the new medium affected the net increase of TEP concentration. The second day after inoculation, when cell density was not significantly different between cultures, the concentration of TEP was higher in cultures grown at a N:P stoichiometry below the Redfield ratio (Fig. 3). This difference was more obvious when the TEP concentration was scaled to either cell number, chl $a$, TPC or TPN (Fig. 4). In all cases, the general trend during the exponential phase was that TEP concentration per unit of biomass (estimated by chl $a$, cell number, etc.) was inversely related to the initial $\mathrm{NO}_{3}{ }^{-}$pulse.

Maximum TEP concentration per volume of culture was directly related to the maximum amount of biomass reached in every culture, which in turn was dependent of the initial nitrate concentration supplied to the culture (Fig. 5).

\section{Carbohydrates in the particulate fraction}

The maximun concentration of particulate carbohydrates $(\mathrm{PCH}$ ) was reached at Day 7 (cultures grown at 25, 75, 150 and $250 \mu \mathrm{mol} \mathrm{NO}_{3}{ }^{-} \mathrm{l}^{-1}$ ) and at Day 10 (cells grown at $450 \mu \mathrm{mol} \mathrm{NO}{ }_{3}^{-}{ }^{-1}$ ) after transferring the cells to the new medium (Fig. 6A). In the senescence phase there was a marked decrease in PCH as previously shown for several other biomass-related variables. Maximum concentrations (14 to $60 \mu \mathrm{g} \mathrm{ml}^{-1}$ ) were directly related to the initial nitrate concentration supplied to the cultures (Fig. 6A).

PCH concentration scaled to TPC showed considerably larger values during the exponential growth phase in N-limited cells (Fig. 6B). Clearly, N limitation increased the net production rate of $\mathrm{PCH}$ in Chaetoceros calcitrans.
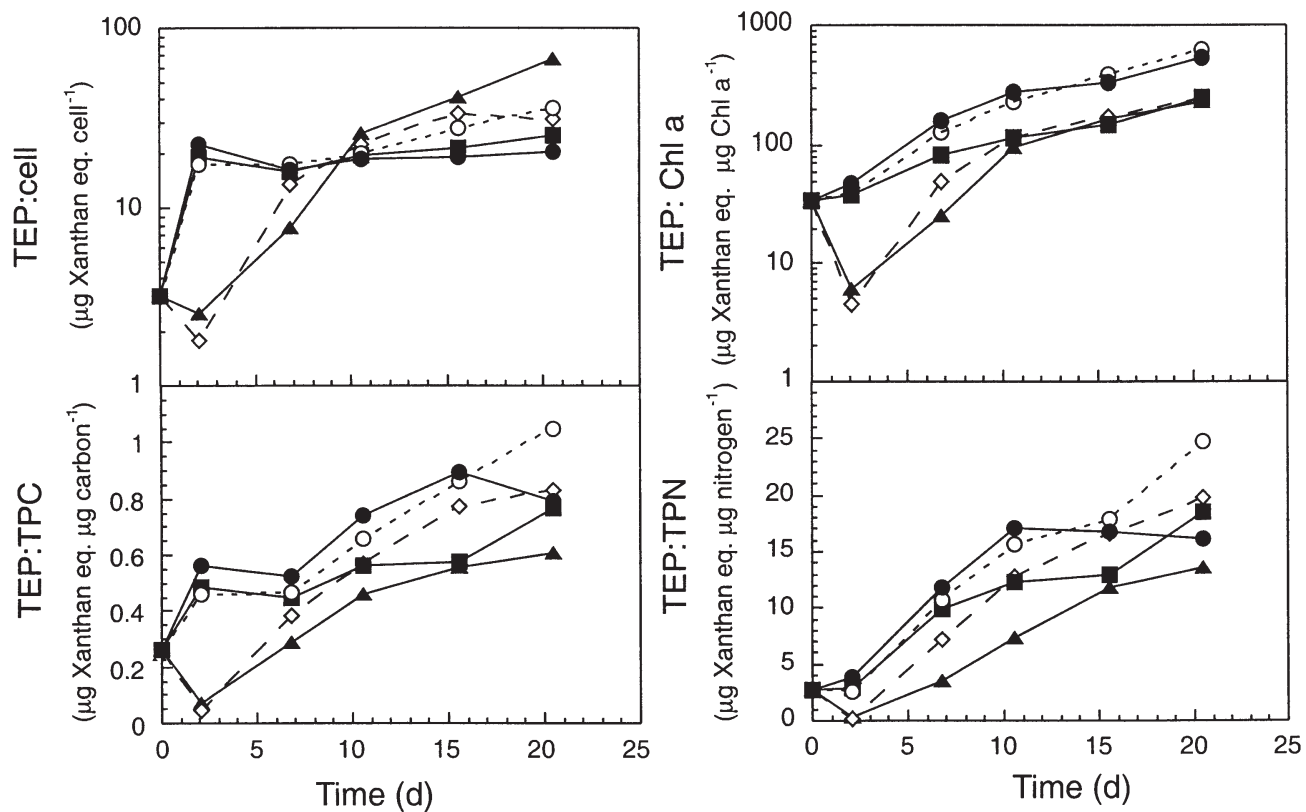

Fig. 4. To compare between cultures the concentration of TEP was scaled to (A) cell number of Chaetoceros calcitrans, (B) chlorophyll $a,(C)$ total particulate carbon (TPC), and (D) total particulate nitrogen (TPN). Cultures were grown at $25(\bullet)$, $75(0), 150(\mathbf{\square}), 250(\diamond)$ and $450(\mathbf{\Delta}) \mu \mathrm{M}$ initial $\mathrm{NO}_{3}{ }^{-}$concentration 

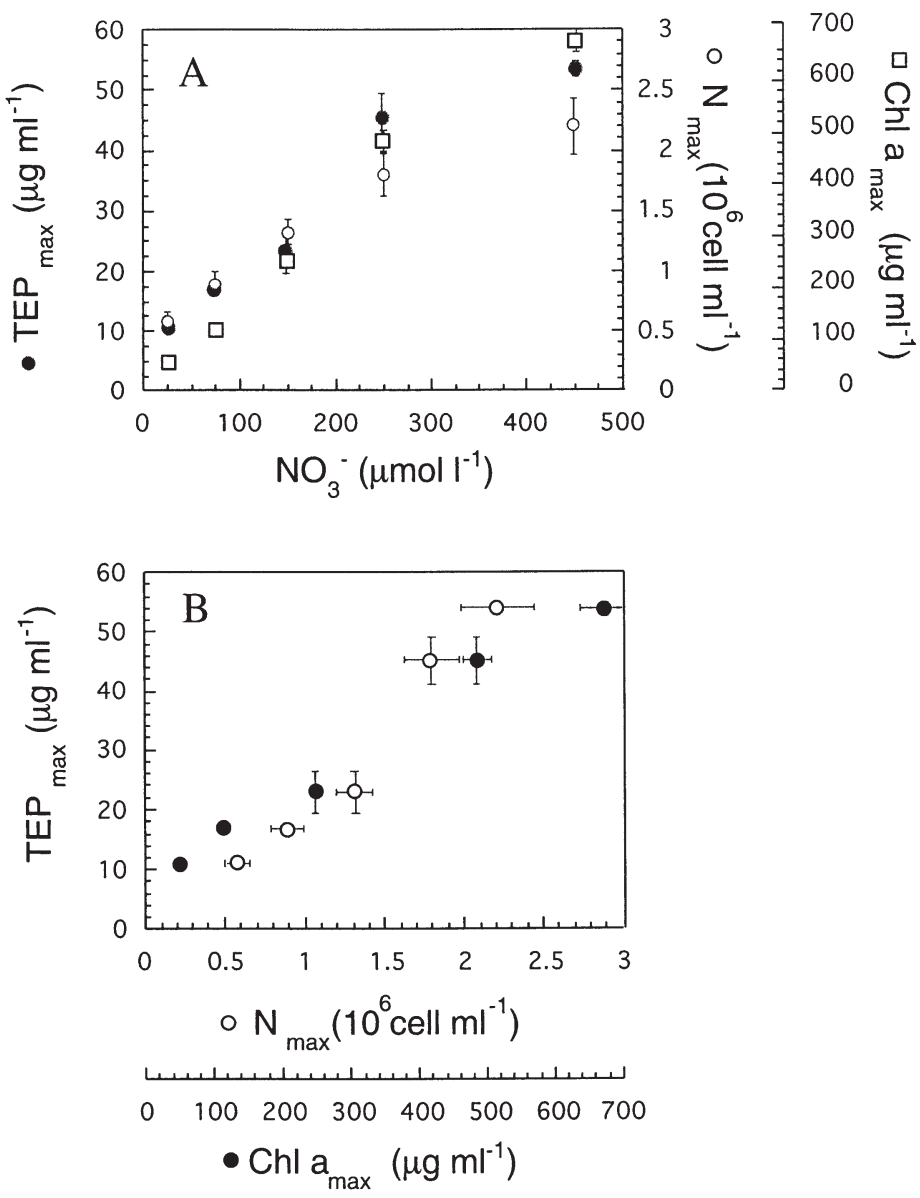

Fig. 5. Relationship between TEP and other biomass-related variables. (A) Maximal concentration of TEP reached in the stationary phase $\left(\mathrm{TEP}_{\max }\right)$, maximal abundance of Chaetoceros calcitrans $\left(\mathrm{N}_{\max }\right)$ and maximal concentration of chlorophyll a $\left(\mathrm{chl} a_{\max }\right)$ plotted against initial $\mathrm{NO}_{3}{ }^{-}$concentration. (B) $\mathrm{TEP}_{\max }$ was linearly related to both $\mathrm{N}_{\max }$ and chl $a_{\max }$

\section{Dissolved organic carbon}

The pore size used in this study to discriminate between dissolved and particulate fractions was $\sim 0.7 \mu \mathrm{m}$ (Whatman GF/F) for all variables except for TEP $(0.4 \mu \mathrm{m}$, Poretics). Therefore, our measurements of DOC would be an overestimation as compared with data obtained using filters with pore sizes of 0.2 or $0.45 \mu \mathrm{m}$.

DOC at the onset of the experiment was $7.4 \pm 3.1 \mu \mathrm{g}$ $\mathrm{C} \mathrm{ml}^{-1}$. This amount was introduced either with the natural seawater when preparing the media (filtered through $0.2 \mu \mathrm{m}$ pore size) or with the cell inoculum. DOC in the cultures grown at 25, 75, and $150 \mu \mathrm{mol}$ $\mathrm{NO}_{3}{ }^{-} \mathrm{I}^{-1}$ oscillated below $14 \mu \mathrm{g} \mathrm{C} \mathrm{ml}{ }^{-1}$ throughout the experiment, although there was a general trend of DOC to increase during the senescent growth phase (Fig. 7). Maximum concentrations were higher in cultures grown at 250 and $450 \mathrm{mmol} \mathrm{NO}_{3}^{-} \mathrm{l}^{-1}$, i.e. 26 and

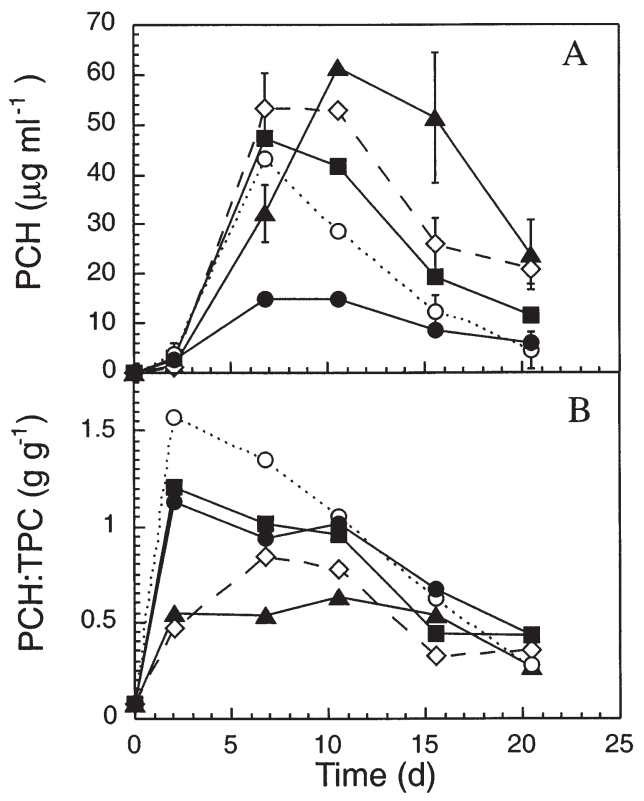

Fig. 6. Time course of the carbohydrate concentration in the particulate fraction $(\mathrm{PCH})$ in batch cultures of Chaetoceros calcitrans grown at $25(\bullet), 75$ (O), $150(\mathbb{\square}), 250(\diamond)$ and $450(\boldsymbol{\Delta}) \mu \mathrm{M}$ initial $\mathrm{NO}_{3}{ }^{-}$concentration. (A) PCH scaled to volume. Plotted data are the mean of 2 replicates. Standard deviation is represented as a bar when it exceeds the symbol size.

(B) $\mathrm{PCH}$ referred to TPC

$44 \mu \mathrm{g} \mathrm{C} \mathrm{ml}^{-1}$ respectively. In this case, DOC showed a clearer trend to increase from the beginning of the experiment. However, similarly to the cultures grown at lower $\mathrm{NO}_{3}{ }^{-}$availability, the DOC net increase was higher during the senescent growth phase, likely due to the release of intracellular content after cell disintegration.

\section{Bacterial abundance}

Initial bacteria abundance was about $1.5 \times 10^{5}$ bacteria $\mathrm{ml}^{-1}$. The number of bacteria in the cultures grown at 25, 75 and $150 \mu \mathrm{M}$ initial $\mathrm{NO}_{3}{ }^{-}$concentration remained lower than $1.6 \times 10^{6}$ bacteria $\mathrm{ml}^{-1}$ throughout the experiment, although a general trend toward a slight increase was observed in the stationary and senescent phases (Fig. 8). Bacterial abundance in the $\mathrm{N}$-sufficient cultures was considerably larger, reaching values as high as 6 and $8 \times 10^{6}$ bacteria $\mathrm{ml}^{-1}$ at the end of the senescent phase in cultures grown at 250 and $450 \mu \mathrm{M}$ initial $\mathrm{NO}_{3}{ }^{-}$concentration. The release of DOC (Fig. 7) occurring in these cultures due to the high rate of cell death and disintegration (Fig. 1) provided the substrate for bacterial growth. 


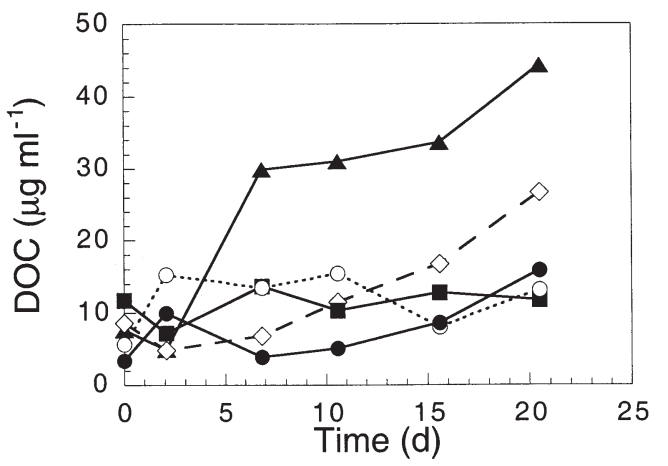

Fig. 7. Time course of dissolved organic carbon (DOC) in batch cultures of Chaetoceros calcitrans grown at $25(\bullet)$, $75(\bigcirc), 150(\boldsymbol{\square}), 250(\diamond)$ and $450(\boldsymbol{\Delta}) \mu \mathrm{M}$ initial $\mathrm{NO}_{3}{ }^{-}$ concentration

\section{DISCUSSION}

In practice, when TEP concentration is determined colorimetrically (Passow \& Alldredge 1995a), it includes both non-living organic particles, larger than $0.4 \mu \mathrm{m}$, formed from polysaccharides excreted presumably by phytoplankton and/or bacteria (Alldredge et al. 1993, Passow et al. 1994), and the extracellular acidic polysaccharides attached to cell surfaces (Decho 1990). In our study, we have not attempted an evaluation of the comparative contribution of both fractions to the spectrophotometric measurement; however cell surface mucus is considered to be negligible compared to 'true' TEP (Passow \& Alldredge 1994, 1995a,b). The term TEP in this paper includes any particle that might be stained by alcian blue in the assay conditions reported in the 'Materials and methods' section after Passow \& Alldredge (1995a). This implies that any acidic polysaccharide present in the sample accessible for staining and larger than $0.4 \mu \mathrm{m}$ contributed to the TEP value measured in this study.

Initial $\mathrm{NO}_{3}{ }^{-}$concentration had a double effect on TEP production by Chaetoceros calcitrans in batch cultures. (1) Since $\mathrm{NO}_{3}{ }^{-}$was used in this study as the limiting nutrient, the initial specific growth rate was determined by $\mathrm{NO}_{3}{ }^{-}$concentration according to the Monod equation. The maximum amount of biomass reached at the end of the exponential growth phase in every culture was, as expected, directly related to the initial $\mathrm{NO}_{3}{ }^{-}$concentration, and qualitatively the same results were obtained for different biomass estimators (Figs. 1, 2 \& 5). The maximum TEP concentration per unit of volume was linearly dependent on the initial $\mathrm{NO}_{3}{ }^{-}$concentration supplied to the cultures (Fig. 5). This suggests that there is a certain level of TEP production per unit of biomass in C. calcitrans grown under variable $\mathrm{N}$ supply and implies that a good linear correlation between TEP concentration and phyto-

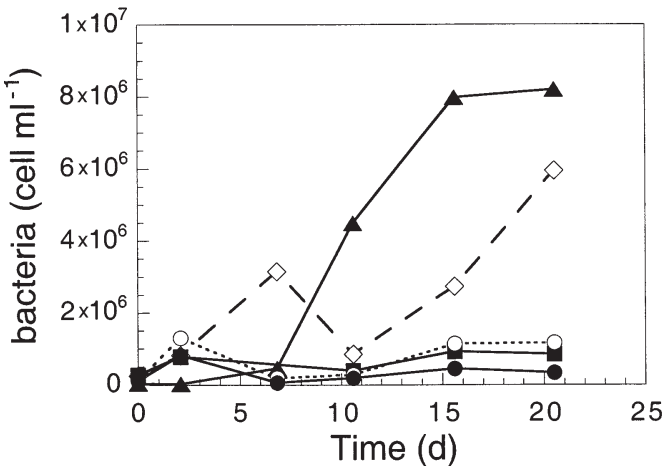

Fig. 8. Bacterial abundance in batch cultures of Chaetoceros calcitrans grown at $25(\bullet), 75(\bigcirc), 150(\mathbf{\square}), 250(\diamond)$ and $450(\boldsymbol{\Delta}) \mu \mathrm{M}$ initial $\mathrm{NO}_{3}^{-}$concentration. Plotted data are the mean of 2 replicates

plankton biomass should also exist. Analysis of our data did reveal a significant linear correlation between the concentration of TEP and both cell number and chl $a$ in cultures of $C$. calcitrans (Fig. 5). TEP concentration was shown to correlate linearly with particulate organic carbon and chl a in a mesocosm experiment and in field studies as well (Passow \& Alldredge 1995a,b). TEP concentration paralleled the general horizontal distribution of chl $a$ in a study in the Ross Sea (Hong et al. 1997), although in this case the relationship between TEP and chl a per unit of volume in the mixed layer was better described through a potential equation. However, when TEP abundance and TEP area were measured by microscopy no significant correlation was found with chl a (Schuster \& Herndl 1995). (2) Our results also suggest that there is a more specific role for nitrate. Clearly, the net rate of TEP production was affected by the initial $\mathrm{NO}_{3}{ }^{-}$concentration. $\mathrm{NO}_{3}{ }^{-}$, as the only source of $\mathrm{N}$, and $\mathrm{PO}_{4}{ }^{3-}$ were provided at different stoichiometric ratios (1.6, 5, 10, 16.6 and 30) to produce a wide range of experimental conditions from N limitation to P limitation (Redfield et al. 1963). The initial net production of TEP per unit of volume was higher by almost 1 order of magnitude in N-limited conditions after transferring the cells (at end of the exponential growth phase) to new fresh media with different N:P stoichiometric ratios (Fig. 3). The differences between the N:P growing conditions, in terms of TEP per unit of volume, were only visible up to the second day after inoculation, when the biomass level was scarcely different between the cultures. Later, the differences in the specific growth rate imposed by the initial $\mathrm{NO}_{3}{ }^{-}$availability resulted in large differences in biomass between cultures, making it necessary to scale TEP concentration to phytoplankton biomass for comparison between distinct growing conditions. The general tendency supported the initial hypothesis. The concentration of TEP normalized to biomass was 
higher in N-limited cultures during the exponential growth phase (Fig. 4). Since TEP are mainly polysaccharides, it seems that under $\mathrm{N}$ limitation, when protein synthesis is reduced, a large proportion of the photosynthetically fixed carbon is channeled, as presumably low $\mathrm{N}$ compounds, to TEP. Decreases in the ratio of protein:carbohydrate have been reported as a frequent response of phytoplankton cultures to N limitation (Myklestad \& Haug 1972, Myklestad 1974). Those authors also found that different species of marine diatoms differed markedly in the organic composition of cells and in the amount of extracellular polysaccharides produced for the same growing conditions. Species of Chaetoceros were found to produce large amounts of extracellular polysaccharides, maintaining relatively high ratios of extracellular polysaccharides to cellular carbohydrates (0.29 to 1.25$)$ compared with species of other genera like Thalassiosira fluviatilis and T. gravida (0.03 and 0.07 respectively) or Skeletonema costatum (0.01). It is not known, as yet, how much of these extracellular dissolved polysaccharides might contribute to TEP formation. However, our results suggest that the effect of $\mathrm{N}$ limitation on TEP production is consistent with the expected effect on carbohydrate content, both extracellular and intracellular, and the protein:carbohydrate ratio.

TEP formation might depend on the turbulence level in every culture. In our experimental conditions, the amount of turbulence introduced by bubbling can be approached by the dissipation rate of turbulent kinetics energy $(\varepsilon), \varepsilon=Q g H V^{-1}$ (Tatterson 1991), where $Q$ is the injected air flux, $g$ is gravitational acceleration, $H$ is the distance covered by bubbles in the water column, and $V$ is the volume of the culture. $Q$ was kept equal in all cultures and constant throughout the experiment. $H$ and $V$ decreased during the experiment as samples were collected. However, there was no difference between treatments because the same volume of sample was collected from each culture. Therefore, although the intensity of the physical processes that can affect the formation of TEP likely changed during the experiment, it changed consistently in all the treatments.

PCH scaled to biomass was larger in N-limited cultures. Similar results have been found by others for different species (Myklestad \& Haug 1972, Vieira \& Myklestad 1986). The differences between N-limited and $\mathrm{N}$-sufficient cultures were larger during the exponential growth phases. TEP and PCH covaried in our experiment during this phase. However, the parallelism between both variables disappeared during the stationary and senescent phase. While TEP concentration remained constant or increased, $\mathrm{PCH}$ decreased markedly. This suggests that TEP and $\mathrm{PCH}$ represent 2 different pools of organic carbon under different regu- lation. In a mesocosm study, TEP concentration was only strongly correlated with the concentration of the highly surface-active carbohydrate fraction (Mopper et al. 1995). In our experiment, it is likely that $\mathrm{PCH}$ are mainly cellular carbohydrates, probably localized intracelullarly, since their time course follows the general trend of cell concentration and chlorophyll as cultures aged. During the senescent phase, PCH concentration strongly decreased, probably because they passed to a dissolved pool due to the high rate of cell lysis found in this phase. Alternatively, part of these carbohydrates must have been used as substrates for the bacteria present in the cultures. In fact, we detected increases both in the concentration of DOC and in the number of bacteria during the senescent phase (Figs. $7 \&$ 8). In both cases, the increases were higher in cultures grown at 250 and $450 \mu \mathrm{M} \mathrm{NO}_{3}^{-}$. Apparently the increases in bacterial density in the senescent phase did not affect TEP concentration, suggesting that, at least under our experimental conditions, TEP were resistant to microbial degradation. In the senescent phase, bacteria likely used DOC from cell lysis as a substrate instead of the particulate fraction accumulated as TEP. Several reasons could explain the preference of bacteria for dissolved substrates in our experimental conditions. The utilization of low molecular weight substrate will save energy since the production of ectoenzymes will be inhibited (Chróst 1991, Obernosterer \& Herndl 1995). TEP are likely to be relatively resistant to microbial degradation due to their chemical composition. TEP are mainly acidic and sulfated polysaccharides enriched in deoxysugars and galactosa (Mopper et al. 1995, Zhou et al. 1998). This high concentration of covalently bonded sulfates could render TEP resistant to bacterial degradation. Preliminary data suggest that the hydrolysis of deoxysugar-containing sulfated polysaccharides are much slower compared to other polysaccharides (Arnosti 2000). Under the conditions of low inorganic nutrient concentration, which prevailed in the cultures during the stationary and senescent phases, the bacterial degradation of TEP could be made difficult if the $\mathrm{C}: \mathrm{N}$ ratio of TEP was higher than 5 (typical C:N stoichiometry of bacteria). Due to their chemical composition TEP are expected to have a high C:N ratio. However, low $\mathrm{C}: \mathrm{N}$ ratios $(7.3 \pm 2.6)$ in TEP produced by bubbling exudates of nitrogen limited diatoms have been reported (Mari 1999). It was suggested that TEP might be able to concentrate, by adsorption, dissolved nitrogen compounds such as amino acids or inorganic nitrogen (Mari 1999). Photosynthetic extracellular release (PER) of phytoplankton is supposed to be the main source of TEP (Passow et al. 1994, Mopper et al. 1995, Mari \& Burd 1998, Mari 1999). However, PER from phytoplankton grown in different conditions 
might not be equally suitable as a substrate for bacteria or for TEP formation. Obernosterer \& Herndl (1995) reported a less efficient utilization by bacteria of PER from $\mathrm{N}$ - and P-limited cultures of Chaetoceros affinis as compared to balanced cultures, suggesting that this would allow PER to coagulate and eventually form mucilage.

TEP are formed by aggregation of precursors $<0.2 \mu \mathrm{m}$ (Passow 2000). The aggregation rate of particles depends on encounter probability and on the stickiness coefficient. The encounter probability, in turn, depends on particle concentration and its size distribution, and on the intensity of the physical processes that make particles collide. The stickiness coefficient is the probability of a particle sticking once it has collided. Nitrogen availability might affect concentration and stickiness according to our results. The increase in $\mathrm{N}$ supply will increase the total number of particles, phytoplankton cells and also all kind of particles derived from them. A higher nitrogen availability will induce an increase in the absolute concentration of TEP as well (Fig. 3), although the relative concentration of TEP to biomass is likely to be lower (Fig. 4).

TEP, due to their chemical composition and fractal nature, have been suggested to facilitated aggregation by increasing the stickiness coefficient (Kiørboe \& Hansen 1993, Passow et al. 1994), although Kiørboe et al. (1998) in a field study did not find a good correlation between TEP concentration and stickiness. However, the proportion of TEP to biomass might have a greater effect on aggregation rate than the absolute concentration of TEP (Passow \& Alldredge 1995b). Dam \& Drapeau (1995) found that the stickiness coefficient was significantly correlated with TEP concentration per unit of chl $a$ in a mesocosm experiment. Nitrogen limitation in cultures of Chaetoceros calcitrans resulted in higher concentration of TEP normalized to biomass as compared with $\mathrm{N}$-sufficient cultures (Fig. 4). Therefore, it can be hypothesized that $\mathrm{N}$ limitation could affect the stickiness coefficient through an increase in the proportion of TEP to biomass.

In addition to the effect of TEP on the stickiness coefficient, its presence increases both the abundance and size of particles present for aggregation. The increase in particle abundance and size may be more determinant than the effect on stickiness for the aggregation rate (Logan et al. 1995).

In conclusion, $\mathrm{NO}_{3}{ }^{-}$availability might have 2 contrary effects on the aggregation dynamics of seston dominated by Chaetoceros: (1) In N-sufficient conditions the total number of particles will be larger, thus increasing collision rate, but decreasing the apparent stickiness coefficient as the concentration of TEP to biomass will be lower. (2) Under N limitation the total number of particles will be lower, thus decreasing col- lision rate. However, phytoplankton cells will produce more carbohydrates, part of which will be located extracellularly either attached to the cell or released as dissolved carbohydrates. PER of N-limited phytoplankton will contribute to increase the abundance and concentration of TEP through coagulation of the surface active fraction (Mopper et al. 1995, Schuster \& Herndl 1995, Mari 1999). The large production of TEP per unit of biomass in this situation will result in an increase of the apparent stickiness coefficient for the whole seston community (Dam \& Drapeau 1995). New experiments should be designed to quantify the conflicting effect of nitrogen limitation on aggregation rate through its contrary action on the total number of particles and stickiness coefficient.

Acknowledgements. We thank Carlos García and Ana Bartual for their help with measurements of TEP, DOC and PCH concentrations. Carlos García, Laura Prieto and Javier Ruíz made helpful comments on a previous draft of the manuscript. This work was supported by grants MAR96-1837 and AMB99-1088 from Comisión Interministerial de Ciencia y Tecnología, and RMN-214 from Plan Andaluz de Investigación. The authors thank the 3 anonymous referees for their comments and suggestions.

\section{LITERATURE CITED}

Alldredge AL, Passow U, Logan B (1993) The existence, abundance, and significance of large transparent exopolymer particles in the ocean. Deep-Sea Res I 40:1131-1140

Arnosti C (2000) Substrate specificity in polysaccharide hydrolysis: contrast between bottom water and sediments. Limnol Oceanogr 45:1112-1119

Bienfang PK, Harrison PJ, Quarmby LM (1982) Sinking rate response to depletion of nitrate, phosphate and silicate in four marine diatoms. Mar Biol 67:295-302

Caperon J, Meyer J (1972) Nitrogen-limited growth of marine phytoplankton. I. Changes in population characteristics with steady-state growth rate. Deep-Sea Res 19:601-618

Chen W, Wagersky PJ (1996) Production of dissolved organic carbon in phytoplankton cultures as measured by hightemperature catalitic oxidation and ultraviolet photooxidation methods. J Plankton Res 18:1201-1211

Chin W, Orellana MV, Verdugo P (1998) Spontaneous assembly of marine dissolved organic mattter into polymer gels. Nature 391:568-572

Chróst RJ (1991) Environmental control of the synthesis and activity of aquatic microbial ectoenzymes. In: Chróst RJ (ed) Microbial enzymes in aquatic environments. Springer, New York, p 29-54

Corzo A, Jiménez-Gómez F, Gordillo FJL, García-Ruíz R, Niell FX (1999) Synechococcus and Prochlorococcus-like populations detected by flow cytometry in a eutrophic reservoir in summer. J Plankton Res 21:1575-1581

Crocker KM, Passow U (1995) Differential aggregation in diatoms. Mar Ecol Prog Ser 117:249-257

Dam HG, Drapeau DT (1995) Coagulation efficiency, organicmatter glues and the dynamics of particles during a phytoplankton bloom in a mesocosm study. Deep-Sea Res II 42: 111-123 
Decho AW (1990) Microbial exopolymer secretions in ocean environments: their role(s) in food webs and marine processes. Oceanogr Mar Biol Annu Rev 28:73-153

Decho AW, Moriarty DJW (1990) Bacterial exopolymer utilization by a harpacticoid copepod: a methodology and results. Limnol Oceanogr 35:1039-1049

del Giorgio PA, Bird DF, Prairie YT, Planas D (1996) Flow cytometric determination of bacterial abundance in lake plankton with the green nucleic stain SYTO 13. Limnol Oceanogr 41:783-789

Dubois M, Gilles KA, Hamilton JK, Reber PA, Smith F (1956) Colorimetric method for determination of sugars and related substances. Ann Chem 28:350-356

Grasshoff K, Ehrhardt M, Kremling K (1983) Methods of seawater analysis. Verlag Chemie, Weinheim

Guillard RRL, Ryther JH (1962) Studies of marine planktonic diatoms. I. Cyclotella nana Hustedt, and Detonula confervacea (Cleve) Gran. Can J Microbiol 8:229-239

Hill PS (1992) Reconciling aggregation theory with observed vertical fluxes following phytoplankton blooms. J Geophys Res 97:2295-2308

Hoagland KD, Rosowski JR, Grez MR, Roemer SC (1993) Diatom extracellular polymeric substances: function, fine structure, chemistry and physiology. J Phycol 29:537-566

Hodson RE, Maccubin AE, Pomeroy LR (1981) Dissolved adenosine triphosphate utilization by free-living and attached bacterioplankton. Mar Biol 27:191-196

Hong Y, Smith WO, White AM (1997) Studies of transparent exopolymer particles (TEP) produced in the Ross Sea (Antarctica) and by Phaeocystis antarctica (Prymnesiophyceae). J Phycol 33:368-376

Jackson GA (1990) A model of the formation of marine algal flocs by physical coagulation processes. Deep-Sea Res 37: $1197-1211$

Jeffrey SW, Humphrey GF (1975) New spectrophotometric equations for determining chlorophylls $\mathrm{a}, \mathrm{b}, \mathrm{c}$ and $\mathrm{c} 2$ in higher plants, algae and natural phytoplankton. Biochem Physiol Pflanz 167:191-194

Kiørboe T, Hansen JLS (1993) Phytoplankton aggregate formation: observations of patterns and mechanisms of cell sticking and the significance of expolymeric material. J Plankton Res 15:993-1018

Kiørboe T, Andersen KP, Dam HG (1990) Coagulation efficiency and aggregate formation in marine phytoplankton. Mar Biol 107:235-245

Kiørboe T, Tiselius P, Mitchell-Innes B, Hansen JLS, Visser AW, Mari X (1998) Intensive aggregate formation with low vertical flux during an upwelling-induced diatom bloom. Limnol Oceanogr 43:104-116

Logan BE, Passow U, Alldredge AL, Grossart HP, Simon M (1995) Rapid formation and sedimentation of large aggregates is predictable from coagulation rates (half-lives) of transparent exopolymer particles (TEP). Deep-Sea Res II 42:203-214

Mari X (1999) Carbon content and C:N ratio of transparent exopolymeric particles (TEP) produced by bubbling exudates of diatoms. Mar Ecol Prog Ser 183:59-71

Mari X, Burd A (1998) Seasonal size spectra of transparent exopolymeric particles (TEP) in a coastal sea and comparison with those predicted using coagulation theory. Mar Ecol Prog Ser 163:63-76

Mopper K, Zhou J, Sri Ramana K, Passow U, Dam HG, Dra-

Editorial responsibility: Fereidoun Rassoulzadegan,

Villefranche-sur-Mer, France peau DT (1995) The role of surface-active carbohydrates in the flocculation of diatom bloom in a mesocosm. DeepSea Res II 42:47-73

Myklestad S (1974) Production of carbohydrates by marine planktonic diatoms. I. Comparison of nine different species in culture. J Exp Mar Biol Ecol 15:261-274

Myklestad S, Haug A (1972) Production of carbohydrates by the marine diatom Chaetoceros affinis var. Willei (Gran) Hustedt. I. Effect of the concentration of nutrients in the culture medium. J Exp Mar Biol Ecol 9:125-136

Nalewajko C, Lean DRS (1972) Growth and excretion in planktonic algae and bacteria. J Phycol 8:361-366

Obernosterer I, Herndl GJ (1995) Phytoplankton extracellular release and bacterial growth: dependence on the inorganic N:P ratio. Mar Ecol Prog Ser 116:247-257

Passow U (2000) Formation of transparent exopolymer particles, TEP, from dissolved precursor material. Mar Ecol Prog Ser 192:1-11

Passow U, Alldredge AL (1994) Distribution, size and bacterial colonization of transparent exopolymer particles (TEP) in the ocean. Mar Ecol Prog Ser 113 185-198

Passow U, Alldredge AL (1995a) A dye-binding assay for the spectrophotometric measurement of transparent exopolymer particles (TEP). Limnol Oceanogr 40:1326-1335

Passow U, Alldredge AL (1995b) Aggregation of a diatom bloom in a mesocosm: the role of transparent exopolymer particles (TEP). Deep-Sea Res 42:99-110

Passow U, Alldredge AL, Logan BE (1994) The role of particulate carbohydrate exudates in the flocculation of diatom blooms. Deep-Sea Res I 41:335-357

Redfield AC, Ketchum BH, Richards FA (1963) The influence of organisms on the composition of sea water. In: Hill MN (ed) The sea. Wiley, New York, p 26-77

Schuster S, Herndl GJ (1995) Formation and significance of transparent exoplymeric particles in the northern Adriatic Sea. Mar Ecol Prog Ser 124:227-236

Shimeta J (1993) Diffusional encounter of submicrometer particles and small cells by suspension feeders. Limnol Oceanogr 38:456-465

Smith DC, Steward GF, Long RA, Azam F (1995) Bacterial mediation of carbon fluxes during a diatom bloom in a mesocosm. Deep-Sea Res II 42:75-97

Tatterson GB (1991) Fluid mixing and gas dispersion in agitated tanks. McGraw-Hill, Inc, New York

Tranvik LJ, Sherr EB, Sherr BF (1993) Uptake and utilization of 'colloidal DOM' by heterotrophic flagellates in seawater. Mar Ecol Prog Ser 92:301-309

Vaulot D, Courties C, Partensky F (1989) A simple method to preserve oceanic phytoplankton for cytometric analyses. Cytometry 10:629-635

Vieira AAH, Myklestad S (1986) Production of extracellular carbohydrate in cultures of Ankistrodesmus densus Kors. (Chlorophyceae). J Plankton Res 8:985-994

Waite AM, Olson RJ, Dam HG, Passow U (1995) Sugarcontaining compounds on the cell surfaces of marine diatoms measured using concanavalin a and flow cytometry. J Phycol 31:925-933

Zhou J, Mopper K, Passow U (1998) The role of surface-active carbohydrates in the formation of transparent exopolymer particles by bubble adsorption of seawater. Limnol Oceanogr 43:1860-1871

Submitted: March 16, 2000; Accepted: September 26, 2000 Proofs received from author(s): November 8, 2000 